Published as: Smart, D. (2020), The origin of an extreme wind gust at Belle-île-enMer, Brittany during storm Alex, 1-2 October 2020. Weather, 75: 392-393. https:// doi.org/10.1002/wea.3888

\title{
Spotlight feature:
}

The origin of an extreme wind gust at Belle-Île-en-Mer, Brittany during Storm Alex 1-2 October 2020

David Smart. UCL Hazard Centre, University College London, UK

\section{Figure}
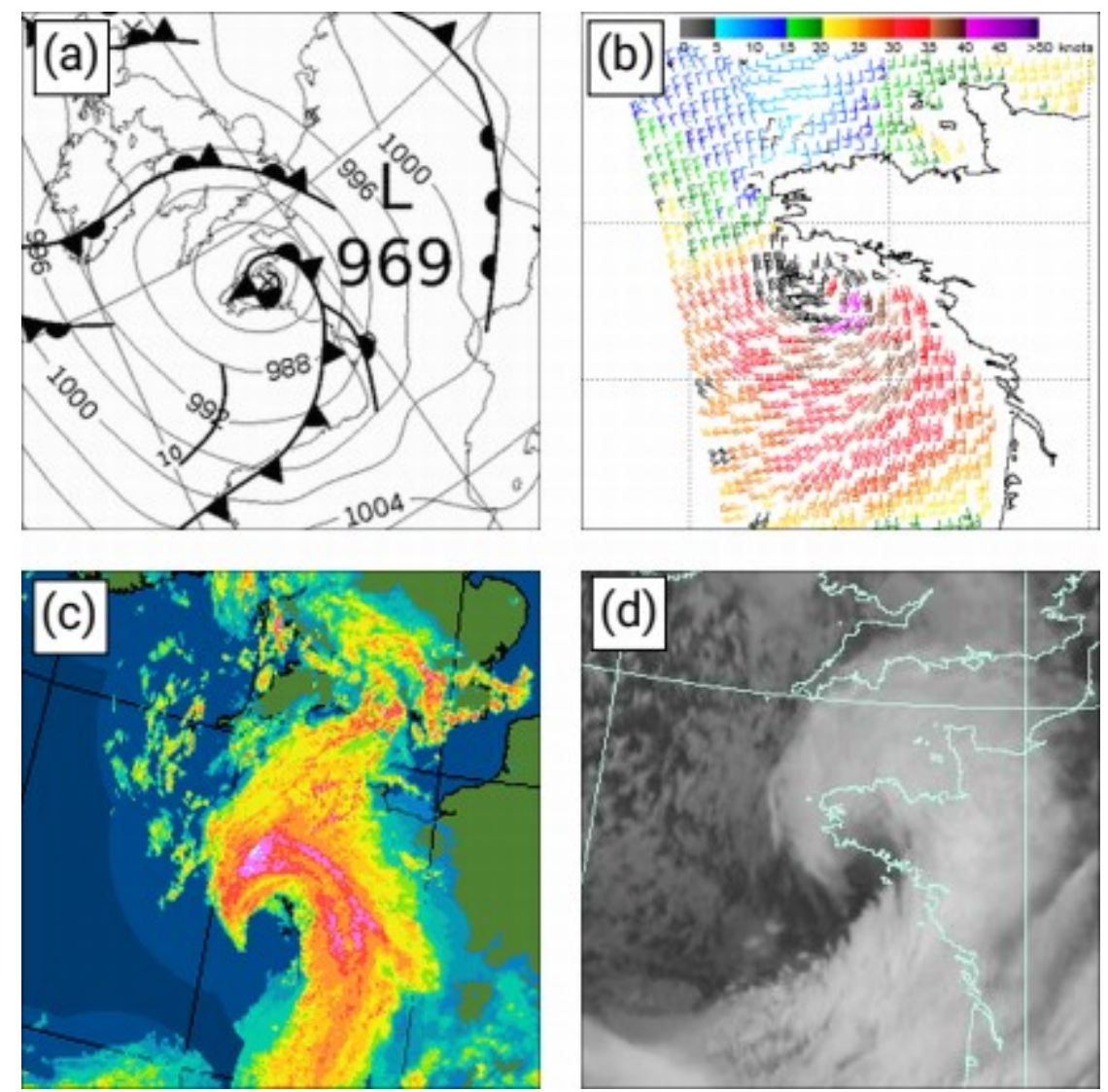

Caption: Figure 1. Observations of Storm Alex on the evening of 1 October 2020. (a) Met Office analysis 00 UTC 2 October 2020. (b) Ocean surface wind vectors from the Advanced Scatterometer (ASCAT) instrument aboard the METOP-A satellite at 2038 UTC on 1 October; wind speed is given in knots and is shaded according to the colour scale; wind vector retrievals flagged as potentially being corrupt due to precipitation are shaded in black (source: NOAA / NESDIS Center for Satellite Applications and Research). (c) EUMETNET OPERA radar snapshot 21 UTC 1 October. (d) $10.8 \mu \mathrm{m}$ infra-red (IR) image valid 21 UTC October. (Met Office analysis is Crown copyright. The geostationary satellite Meteosat Second Generation (MSG) image is provided courtesy of EUMETSAT and the CEDA.)

Text: Storm Alex was named by the French national meteorological agency Météo-France on 30 September 2020. Met Office analyses show that the storm deepened from a central pressure of about $1012 \mathrm{hPa}$ at 00 UTC 1 October to $968 \mathrm{hPa}$ on 06 UTC 2 October. A sub-section of the Met Office analysis valid 00 UTC 1 October is shown in Figure 1(a) when the central pressure was analysed as $969 \mathrm{hPa}$. The storm brought strong winds and record rainfall to the United Kingdom and France, the observations and effects of which are summarised by Kendon (2020). 
A snapshot from the METOP-A satellite Advanced Scatterometer (ASCAT) instrument pass at 2038 UTC on the evening of the $1^{\text {st }}$ is shown in Figure 1(b) capturing the intense circulation of the storm as the strongest winds neared the coast of northwest France. This can be compared with a network radar composite and an infra-red (IR) image (Figures 2(c) and 2(d) both valid at 21 UTC. The scatterometer wind vectors suggest the presence of a bent-back front (BBF) and cold-conveyor belt (CCB) jet in the northern and western quadrants of the storm and strong south-westerly winds in the dry slot/frontal fracture region consistent with the Shapiro-Keyser model of cyclone structure (Shapiro and Keyser, 1990). The radar image shows banding in the BBF and a sharp cloud head 'hook' feature. Filamentation of cloud tops and the 'hook' feature can also be discerned in the IR satellite image. The strong south-westerly winds in the dry slot suggest a sting jet was present and reaching the ocean surface at this time. Analysis of an operational model run also provided evidence for the presence of air parcel trajectories consistent with the presence of a sting jet reaching the boundary layer top (not shown). Seasonally warm sea surface temperatures (SSTs) may have helped to reduce the boundary layer static stability and aided the downward transfer of momentum in the form of wind gusts. The reader is referred to Schultz \& Browning (2017) and references therein for an explanations of the terms and concepts used here. Another recent sting jet storm in the vicinity of the UK is described in the October issue Spotlight feature (Smart, 2020).

Examination of surface wind observations over land and off-shore of northwest France indicate the occurrence of strong surface gusts overnight 1-2 October widely in excess of 40kn (46 mph) with some in excess of $65 \mathrm{kn}(75 \mathrm{mph})$ leading to 80,000 homes losing power and widespread disruption in the region (source: France3, 2020). The strongest gust observed was $100 \mathrm{kn}(116 \mathrm{mph})$ on the island of Belle-Île-en-Mer off the Brittany coast (47.33 N, $3.18 \mathrm{~W})$ just before 22 UTC. The island is situated in a very exposed location and it might be tempting to ascribe this extreme gust to the passage of the sting jet given the imagery presented above. However, examination of the record shows that the peak in wind speeds occurred as the wind veered abruptly from a south-westerly to a north-westerly direction indicating the arrival of the leading edge of the CCB jet (Smart and Browning, 2014), although elements of the sting jet airmass may well have been in close proximity at the time. The nature of the interaction between the sting jet and CCB jet in this critical phase of rapidly deepening Shapiro-Keyser storms is an area requiring further investigation and research.

\section{References}

France3, 2020. https://france3-regions.francetvinfo.fr/bretagne/morbihan/tempete-alex-rafales-186kmh-belle-ile-80-000-foyers-electricite-morbihan-1879902.html (in French, accessed 5 November 2020)

Kendon, M. 2020. Storm Alex and heavy rain. https://www.metoffice.gov.uk/binaries/content/assets/metofficegovuk/pdf/weather/learn-about/ukpast-events/interesting/2020/2020 09 storm alex.pdf (accessed 30 October 2020).

Schultz DM, Browning KA. 2017. What is a sting jet? Weather 72: 63-66.

Smart, D. (2020), Two severe extratropical cyclones over the UK and Ireland, August 2020. Weather, 75: 316-317.

Smart, D.J. and Browning, K.A. (2014), Attribution of strong winds to a cold conveyor belt and sting jet. Q.J.R. Meteorol. Soc., 140: 595-610.

Shapiro, M.A. and Keyser, D., 1990. Fronts, jet streams and the tropopause. In Extratropical cyclones (pp. 167-191). American Meteorological Society, Boston, MA. 